\title{
Stress analysis on main landing gear for small aircraft
}

\author{
A.S. A. Al-banaa \\ Mechanical Eng, dept. \\ Mosul University
}

\author{
Prof .Dr. S. M.J.Ali \\ Mechanical Eng, dept. \\ Mosul University
}

\author{
Dr. Rui Pires \\ Aerospace Engineering \\ Cranfield University -UK
}

\begin{abstract}
Main landing gear is important part in aircraft, its help the aircraft to takeoff ,landing, and taxing in the ground .This part subject to high stress at landing due to impact, there are two important force act on landing gear during touch, Normal force and a spin-up back force .Normal Force is a great force that act on landing gear and its generate due to Normal impact and its cause to bend landing gear to up, this force can be calculated form Newton second law, and the spin-up back force generated at touch when the tire not rotate causing the landing gear leg to bend to backward the value of this value can be assumed equals to 0.5 from the normal force. In this study this forces type are considered to make stress analysis of the landing gear for Cessna 152 during touchdown time, after that three model are considered to reduce value of stress on this landing gear by keeping the dimension and material as on original model and making positive curves on the landing gear leg, and shown that when making the positive curve this will reduce the value of the stress and deflection on the landing gear depending on the principle of bending moment in the beams.

Keywords: landing gear. Normal Force. Stress. Stroke Length. Deflection.

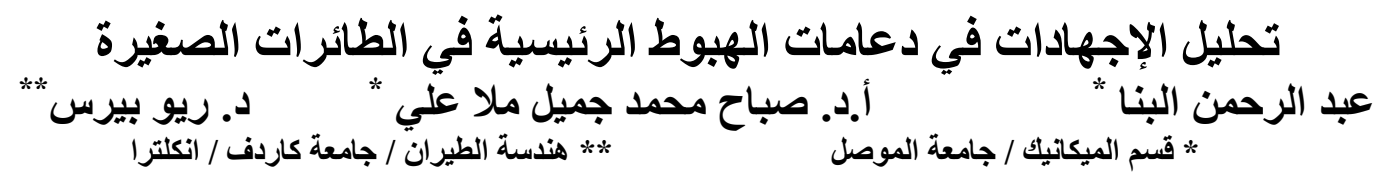

\section{الخلاصة}

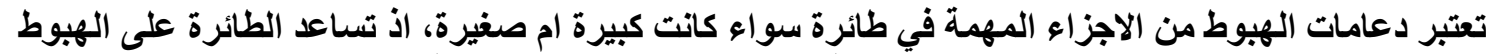

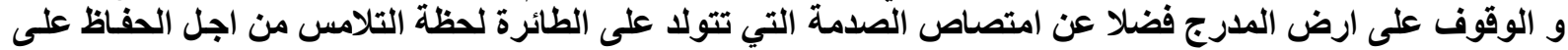
هيكل الطائرة من الانهيار. للطائرات الصغيرة مثل طائرة

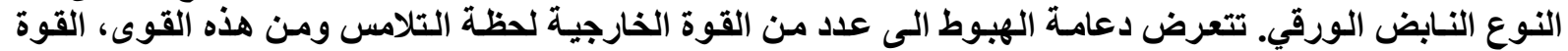

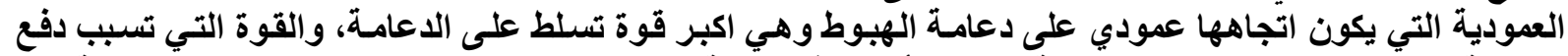

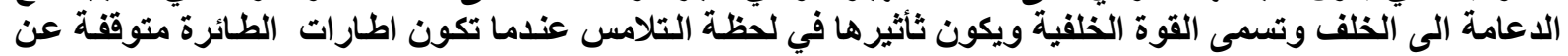

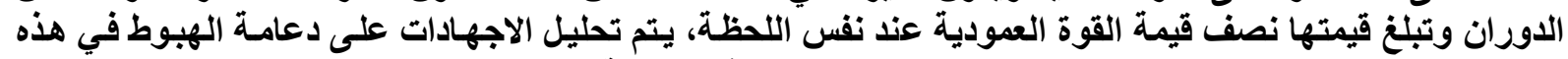

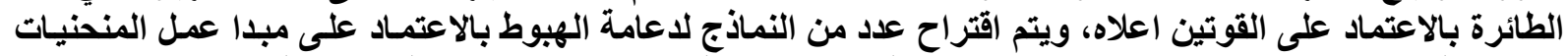

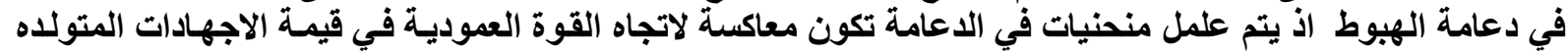




\section{1- Introduction}

The main landing of any aircraft has three advantages, enable the aircraft to stand on the runway, and to absorb the energy generated at landing stage by the shock absorber attached in the landing gear to product the fuselage of aircraft from failure, and help the aircraft for taxiing and rolling of the runway. The landing gear located in under the nose of the aircraft and under the wing depended on the arrangement of the landing gear. There are two arrangements of the landing gear, conventional landing gear where one landing strut located aft the C.G. of the aircraft at two struts located forward the C.G. The tricycle landing gear where one strut located forward the C.G for aircraft, and two strut located aft C.G. The two basic types of landing gear are retractable landing gear, in this type the landing system can be retract in the fuselage or in the wing of aircraft. The fixed landing gear in which is not retracted the aircraft such as in small aircraft. The landing gear subjected to high impact loads at landing therefore, all the research about the landing gear for determining the stress, deformations and a fatigue focuses on this critical point, this part subjects to high stress at landing due to impact, there are two important forces act on landing gear during touch, Normal force and a spin-up back force .Normal Force is a great force that act on landing gear and its generate due to normal impact and its cause to bend landing gear to up, the spin-up back force generated at touch when the tire not rotate, causing the landing gear leg to bend to backward the value of this value can be assumed equals to 0.5 from the normal force.

For producing aircraft landing gear there are many materials can be used for this purpose, such as $300 \mathrm{M}$ steel, 4130 steel, 4340 steel, and ultra-high strength alloy such as AERMET 100 or composite material, the selection of the material for landing gear depended on type, size, and the purpose from the aircraft. Also the cost of the material depends on the material used. For light aircraft can be used steel alloy of aluminium alloy, while in large civil aircrafts or fighter aircrafts can be used ultra-high strength alloy or composite material.

There are many research about the landing gear, for different type of aircraft, and most of this study were focused on the stress on the landing gear at touch touchdown because its critical point for any design, the aircraft used in the test is small or unmanned aerial vehicle (UAV) for composite landing gear or metal landing gear and review of study are showed below;

In 2009 (Jian,et al., [1]) was marked a study of the optimaization of the landing gear for small landing gear retractable landing gear based on the fatigue of the landing gear at toucdown by a simiulation of the landing gear at touch and determination the location of the maximum stress generated at touch time, and for that part, determaination the number of cycle for fatigue, aftre that a optimization process on that part by removing some matieral trying to make weight reducion and results showed that part is far from yeild point for the material and for fatigue region. In 2008, it had been studied the optimization of the landing gear in UAV aircraft depended on pervious study for (Goyal, 2002) except the material used for the leg is steel instead of composite material. the landing gear optimization process by removing material from law stress region, but a stress consternations were observed in the landing gear leg(Al Qahtani \& Abahlali [2]). In 2003, it was simiulated the landing gear for samll aircraft by using PATRAN/NASTRAN, to determine the static stress analysis of the landing gear depending on FAR23 and compared the results of the similuation with actual model by using strain gauges on the landng gear and the results showed that the programe produced good results and value of errors was about 10\% (Plhal [3]). In 2002, it had been studied the stress and deflections on the landing gear for UAV aircraft made of composite material by using ANSYS V5, the axial and uniaxial reinforcements were tested, the results showed the stress 
and deflection in the case of axial reinforcement was much better that in case of uniaxial direction of the reinforcement (Goyal [4]). In 1995, it had been simulated the landing gear for BERKUT aircraft by using STARDYNE, and determined the stress generated on the root of the landing gear (supporting region) and compared the results with manual solution by using mathematical model equations (Morrison,et al[5]).

In this study an optimization of the stress and deflection analysis on the small aircraft Cessna 152 landing gear, can be done by FE analysis by using PATRAN/NASTRAN which is commercially test in aerospace applications by NACA. First by determining the value of stress on the original model for landing gear due to effect on normal force and a spin-up drag force, after that a three different models are suggested to reduce the value of stress generated on this models by same material and same dimension used in the original model.

\section{2 - Mathematical Analysis of the Landing Gear}

\section{2-1 Actual Landing Gear Analysis Procedure}

During landing process, the landing gear subject to high impact force due to descent velocity or (Sink Velocity), In FAA design the condition each main wheel should be required to carry at least the aircraft gross weight per FAR23.473, but in landing condition the landing gear should require to carry $2 \mathrm{~g}$ of the impact loads on each landing.

The loads on the landing gear are not only the normal force. When the tires contact the ground they are not rotating, During the brief fraction of a second it takes for them to spin up, the exert a large rearward force by friction with the runway, this force can be assumed half of the vertical force, when the tire rotating at the correct speed the rearward force is relieved and the gear strut "spring -back" forward, causing back deflection load equal to or greater than the spin- up load (Raymer [6])

The landing gear type in light aircraft like Cessna152, is a fixed landing gear, and the shock absorber type is a leaf spring type, which depend on the elastic properties of the landing gear legs and the damping effect of tyre sideslip on the ground and its defected to the up direction when subjected to normal force (Raymer, [6]) as schematically shown in Fig (1).

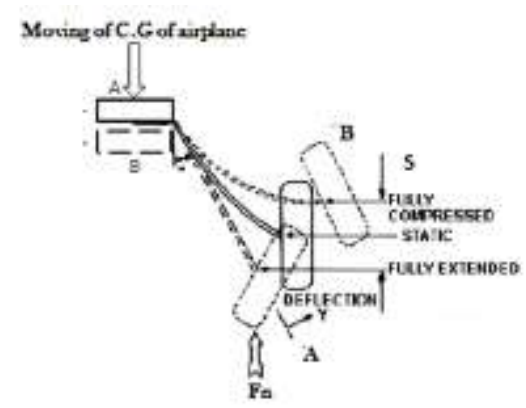

Fig (1) Stroke in the steel leaf spring landing gear

\section{2-1- 1 Determining the deflection or stroke length of the landing gear:}

The required deflection of the shock absorber system depend upon the vertical velocity at touchdown, the shock absorber material, and the amount of wing lift still available after touchdown, as the rough rule of thumb, the stroke of inches approximately equal the vertical velocity at touchdown in(ft/s). (Raymer, [6]) The rate of vertical velocity or (sink speed) at touchdown is established in various specifications for deferent types of aircraft, the values of sink speed are listed in the table (1) 
Al-Rafidain Engineering

Table(2) loads factor in FAR for landing gear

\begin{tabular}{lc}
\hline \hline Aircraft type & $\mathrm{N}_{\text {gear }}$ \\
\hline Large bomber & $2.0-3$ \\
Commercial & $2.7-3$ \\
General aviation & 3 \\
Air Force fighter & $3.0-4$ \\
Navy fighter & $5.0-6$ \\
\hline \hline
\end{tabular}

Table (1) vertical speed on airplane at landing

\begin{tabular}{|l|l|}
\cline { 2 - 2 } \multicolumn{1}{c|}{} & Design touchdown rates \\
\hline FAR 23 & $4.4\left(\mathrm{~W} / \mathrm{S}^{\circ} \mathrm{\lambda}^{0.25}\right.$ tos \\
\hline FAR 25 & $12 \mathrm{fps}$ \\
\hline USAF & $10 \mathrm{fps}$ \\
\hline \multirow{3}{*}{ USN } & $10 \mathrm{fps}$ for transports \\
\cline { 2 - 3 } & 17 fps for other non-carrier based arplanes \\
\cline { 2 - 3 } & $22 \mathrm{fps}$ for carrier based airplanes \\
\hline
\end{tabular}

The type of the landing gear in this study is steel leaf spring and in this type, the energy is absorbed by deformation of the landing gear leg, and it is absorbed the kinetic energy converted it to deflection and friction inside the material layer, (Milano [7]) as shown in the Fig(1), the efficiency of this type of landing gear is 0.5 as shown in the table (2) The Kinetic energy generated at landing is:

$\Delta K . E=0.5 W V_{n 1}^{2}$

Where:

W: Weight of aircraft.

$V_{n 1}$ : Verical velocity of airplane at touchdown $(\mathrm{m} / \mathrm{sec})$, the values of sink speed are listed in the table (2-1), from the table, the values of sink speed depend on many standards, this study will depend on FAR23, according to this standard the $V_{n 1}$ can calculated by $4.4(W / A)^{0.25}$, and should not be less than $7 \mathrm{ft} / \mathrm{sec}$ and not more than $10 \mathrm{ft} / \mathrm{sec}$,

The total energy absorbed by the landing gear is:

$E_{\text {absorb }}=W \cdot g \cdot N_{g}\left(\eta_{t} \cdot S_{t}+\eta_{s} \cdot S_{s}\right)$

Where:

$N_{g}$ : Gear load factor, which determine how much load the gear passes to the airframe

$S_{t}, S_{g}$ : Stroke length for tire and landing gear leg respectively.

$\eta_{t}, \eta_{s}$ : Efficiency of the tire and landing gear leg respectively.

From Eqs., (1) and (2), yield Eqs, (4)

$W \cdot g \cdot N_{g}\left(\eta_{t} \cdot S_{t}+\eta_{s} \cdot S_{s}\right)=0.5 W V_{n 1}^{2}$

$S_{s}=\frac{V_{1 n}^{N}}{2 g\left(N_{g} \cdot N_{g}\right)}-\frac{n_{t}}{n_{g}} S_{t}$

From the above equations the requirement to calculate the stroke length after neglecting the tire system is $V_{n 1}$ and if it assumed $7 \mathrm{ft} / \mathrm{sec}(2.38344 \mathrm{~m} / \mathrm{sec})$ and weight of aircraft $757 \mathrm{Kg}$ [8], the value of stroke will be $0.21456 \mathrm{~m}$.

\section{2-1-2 Determining of the loads at touchdown:}

The dynamic load on each landing gear can be calculated, by assuming the impact force will be $2 \mathrm{~g}$, as in FAR 23, by using the Newton second law, $F_{n}=\frac{W}{2} \cdot a$

And because the total mass on the landing gear is $2 \mathrm{~g}$ at landing therefore 
$F_{n}=W \cdot a$

The acceleration at touchdown can be calculated from equation (6), yield the value of acceleration is $9.467 \mathrm{~m} / \mathrm{sec}^{2}$.

$V_{n}^{2}=V_{0}^{2}+2 a S_{s}$

As a monitored above the spin-up back load generated at touch causing deflection on the landing gear backward, this force occurs before the starting to rotate, if the value of this force is about half of normal force at touchdown, so to determine this force the following step is required,

$F_{\text {back }}=0.5 \times F_{n}$

By applying eq(6) for normal force will lead to $7.1665 \mathrm{KN}$, and from eq (8) the value of back force is $3.58325 \mathrm{KN}$.

\section{3-Stress Analysis of the original landing gear}

The values of the dynamic loads are larger than the static loads and all the design loads should be due to the effect of these forces. There are many forces affected in the landing gear at touchdown, in this study two forces are considered to determine the stress on the landing gear, which is the normal force which generated by the effect of descant velocity and spin up back force which cause the landing gear deflected to the backward directions. The original model of the landing gear is shown in Fig (2)

Material of the landing gear, 98S steel

Yield, tensile strength $=850 \mathrm{MPa}$, Ultimate, tensile strength $=1158 \mathrm{MPa}$

Boundary condition :Upper end is fixed (No translated or Rotations)

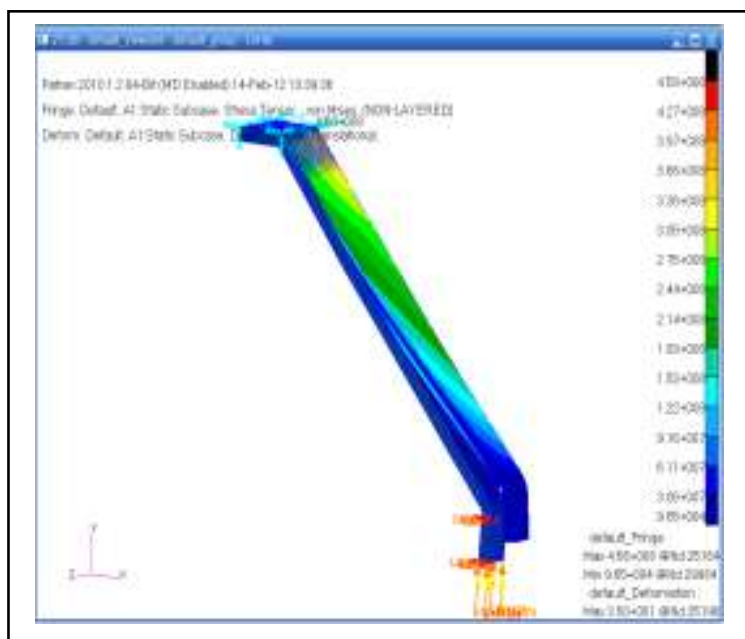

Fig (3) Stress on the original landing gear

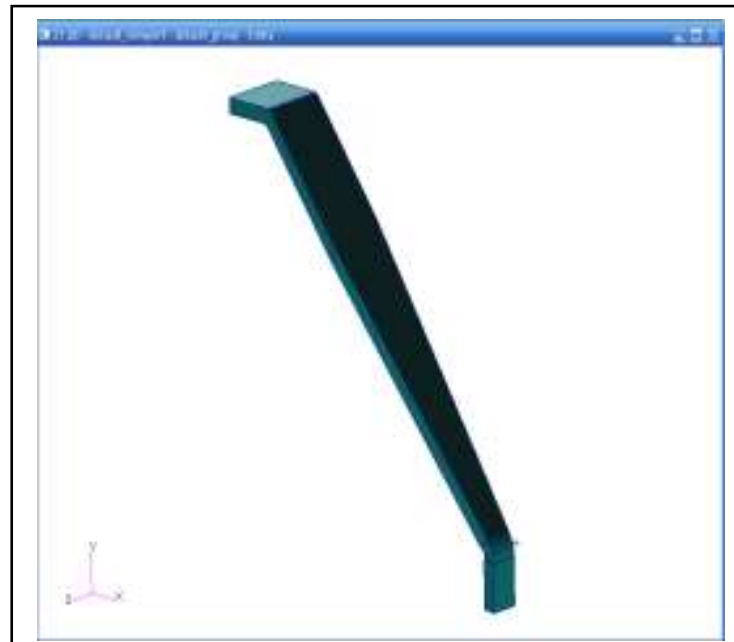

Fig (2) Original model landing gear for Cessna 152

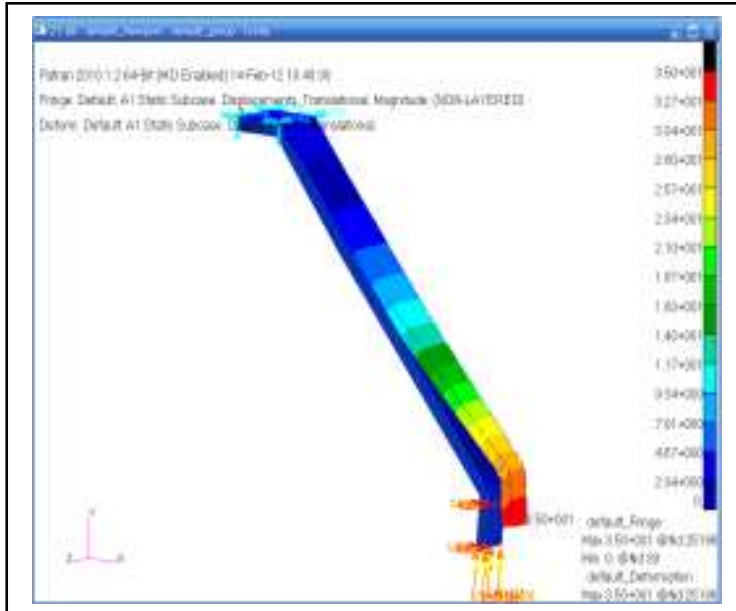

Fig (4) deflection on the Original landing gear 
Applying these forces in the PATRAN/NASTRAN program at element size $9 \mathrm{~mm}$, and the results at this mesh size are $458 \mathrm{MPa}$ for maximum stress, and $35.1 \mathrm{~mm}$ for maximum deflection as shown in the Fig (3), and Fig (4).

\section{4- Suggested Model for Landing Gear}

Two models for landing gear are considered to reduce the value of the maximum stress, the modification on this depends on changing the shape of the landing gear leg, by making the leg divided in two parts (i.e. not straight as the original model), the material of the landing gear will be same in the two cases, also the hieght of the leg and the horizontal distance will be same.

\section{4 - 1 stress analysis in suggest model-1 landing gear leg:}

In this model the landing gear is divided into two parts, the upper part in the vertical direction and the lower part as a previous one but the lower part is not straight and take convex shape as in the Fig(5), the purpose of divided two parts to reduce the value of the inclined part, and convex to generated initial curvature in opposite direction of the normal force, and the horizontal and vertical distance for the gear is the same.
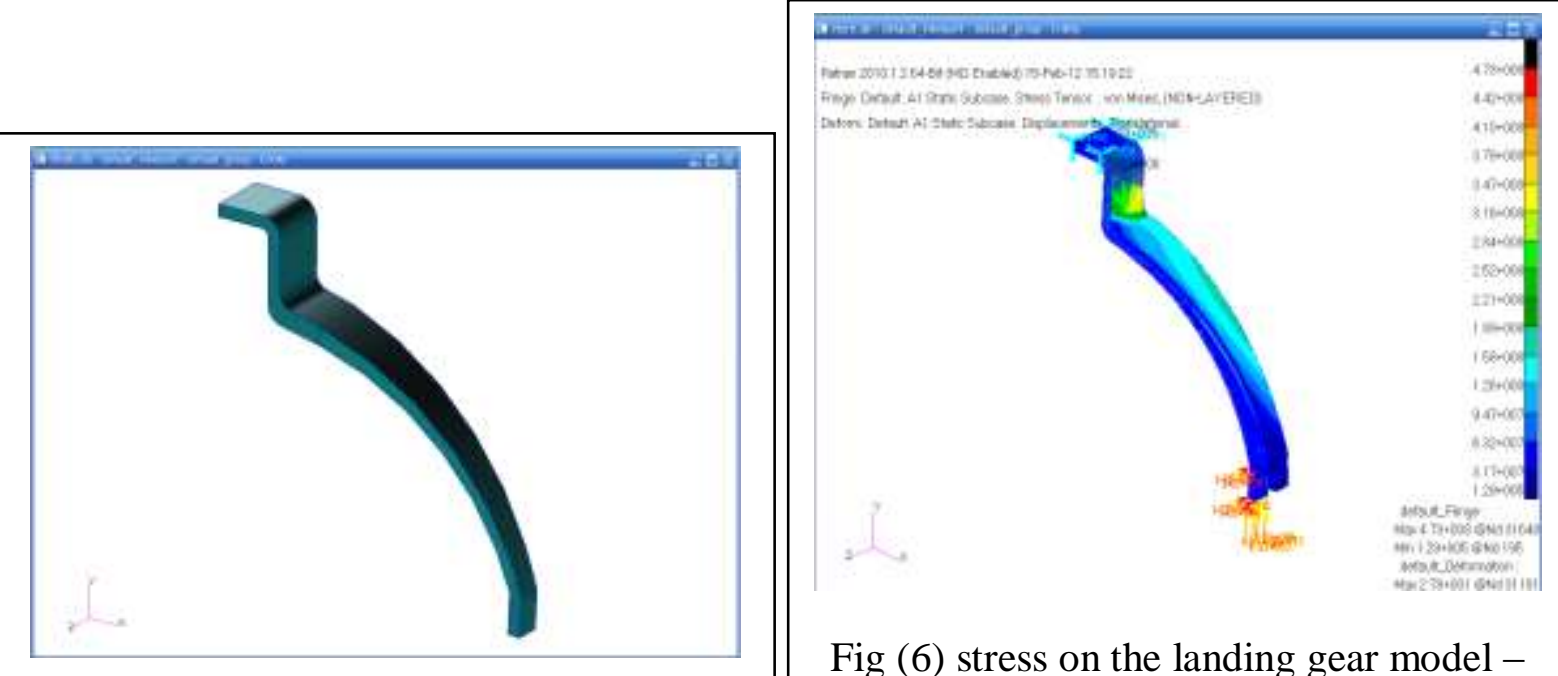

Fig (6) stress on the landing gear model -

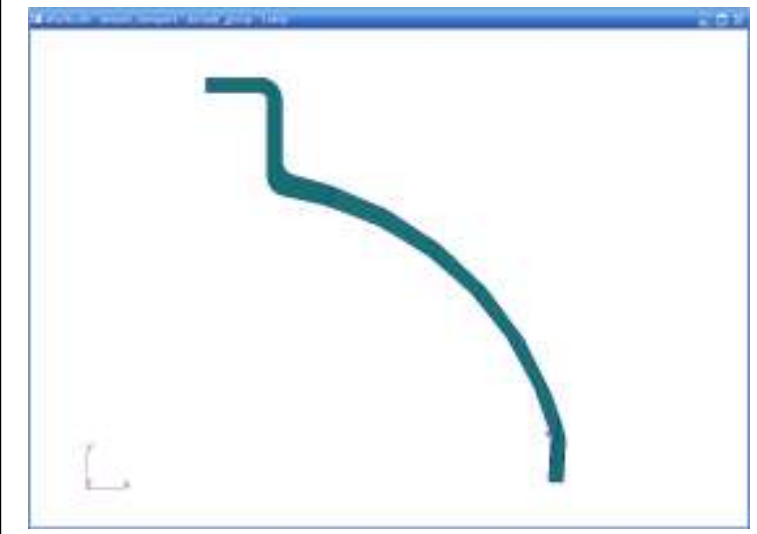

Fig (5) suggest model -1

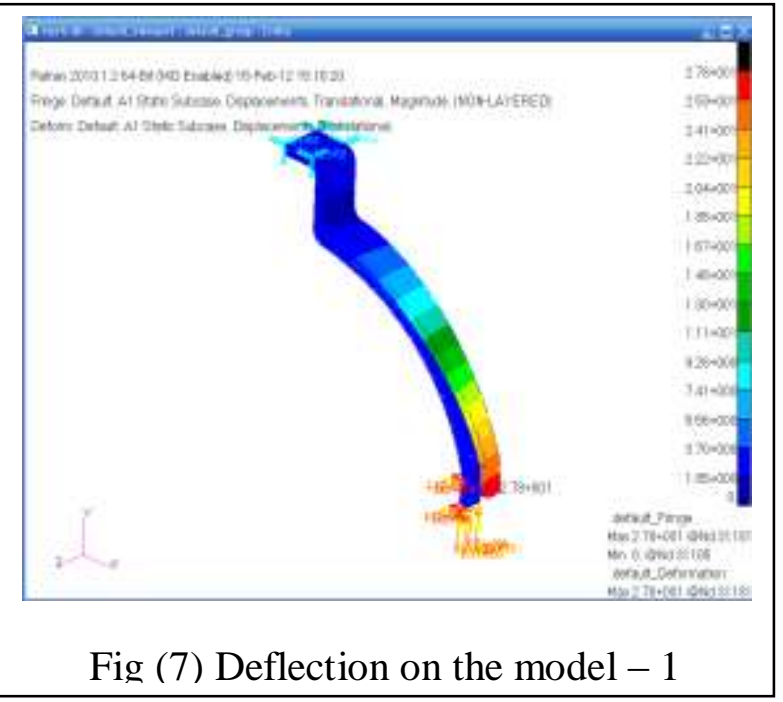


By applying the same boundary conditions on the original model, At initial value of mesh at $9 \mathrm{~mm}$ the value of the maximum stress by using PATRAN /NASTRN program is $473 \mathrm{MPa}$, and the deflection $27.8 \mathrm{~mm}$ as shown in Fig(6) and Fig(7) resp.,

\section{4 - 1 stress analysis in suggest model-1 landing gear leg:}

In this model there is no changing in the shape of the landing gear (i.e the landing gear will not divided into two regions as in the previous model) to reduce the stress concentrations generated in the region between horizontal and convex. There is only one deference from the original modal, the landing gear in not straight and it is convex, as shown in the Fig (8).

By applying the same boundary conditions on the original model, At initial value of mesh at $9 \mathrm{~mm}$ the value of the maximum stress by using the PATRAN /NASTRN program is 419MPa, and the deflection $18.1 \mathrm{~mm}$ as shown in Fig(9) and Fig(10) resp.,
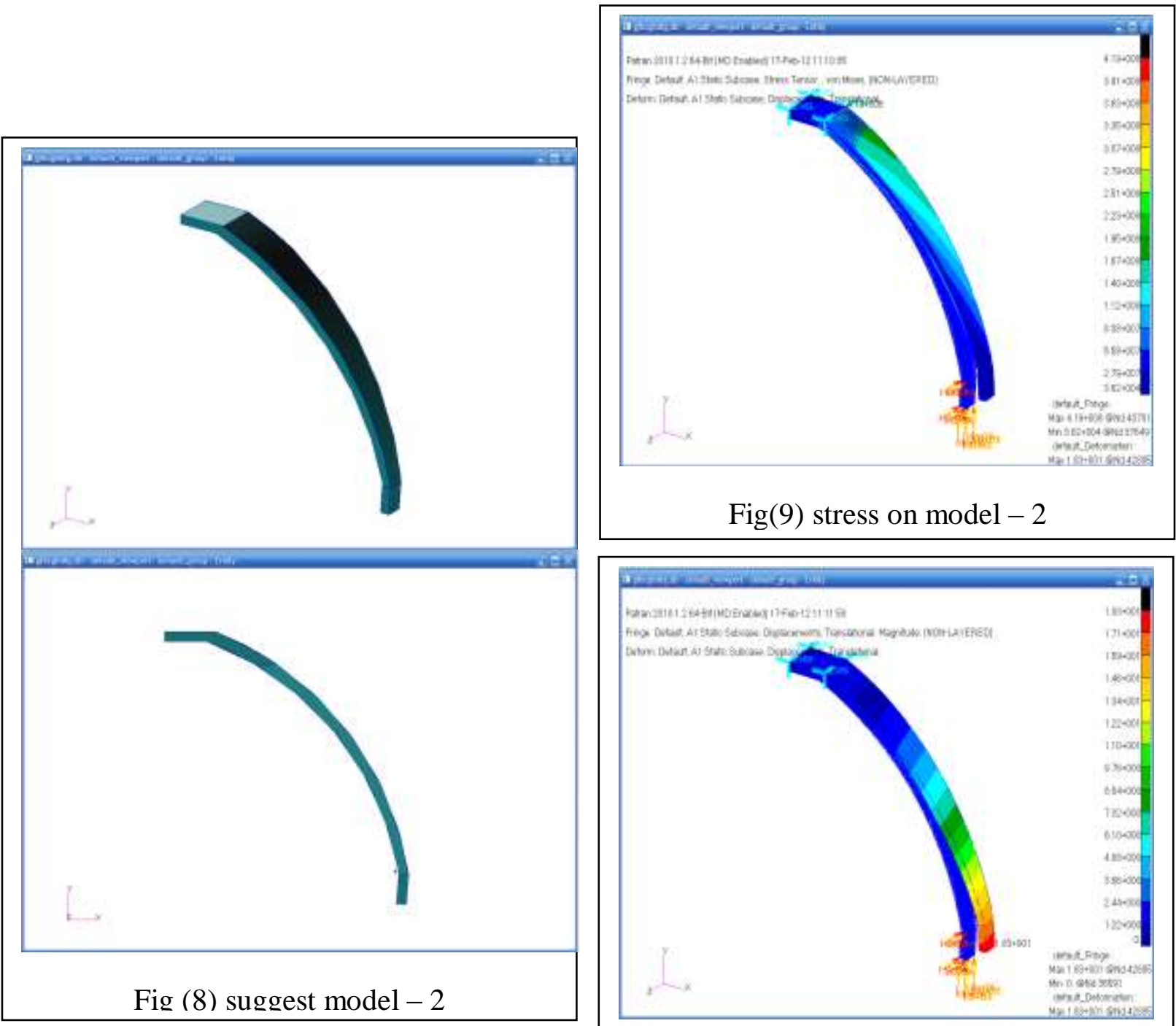

Fig (10) deflection on the model - 2

on the models, we can find the value of stress in the original model is about $458 \mathrm{MPa}$ and deflection is about $35.1 \mathrm{~mm}$. The weight of model is about $20 \mathrm{Kg}$. In model- 1 the shape of 
the landing gear leg is divided into two parts in order to reduce the length of the inclined part to reduce the value of deflection. Moreover it has been made in an arc convex (reverse direction of the normal force), the value of deflection become equal to $27 \mathrm{~mm}$, but the value of stress is become $478 \mathrm{MPa}$, and its higher than the original model, because a stress concentration area between convex arc and the straight part. In model -2 the landing gear remains as same as the original model, but there is a simple deference in which the inclined part is converted from straight to convex shape, and the mass is about $21.5 \mathrm{Kg}$ and the value of stress is about $420 \mathrm{Mpa}$. and it is lower than the previous models. As can be seen model -2 is heavier than the original model, but this can be fixed by removing the material from the lower stress area. The value of the deflection is round $18.1 \mathrm{~mm}$, it is lower than the original model, depending on the principle of the curvature in the beams. Furthermore, the deflection on this model it is lower than the $2^{\text {nd }}$ model, because there is no couple generated on the region between straight part and convex part which try to lift the free end of the landing gear.

\section{6- Conclusion}

From this study the stresses in the landing gear, can be reduced by changing the shape of the landing gear, keeping the same mean dimensions between the models like (height and thickness). When the value of stresses reduced this mean, that the material used can be changed to lower material properties and this mean reducing the cost of landing gear, but not overall cost of the landing gear because there are other factors such, production process which is not considered in this study.

\section{References}

1- Jian, M., Caijun, X., Yaquan, D., \& Hong, W. (2009). optimization method of multi- body structure based on the fatigue life. Retrieved 2011, from Nanjing University of Areonautics and Astronautics /China.

2- Alqahtani, M., \& Albahlali, E. (2008). Design of light landing gear . Retrieved 2011, from http://faculty.ksu.edu.sa/moalqahtani/Design\%20of\%20Light\%20Landing\%20Gear/Desig n\%20of\%20Light\%20Landing\%20gear.pdf

3- Goyal, A. (2002). Light Aircraft MAin Landing Gear Design and Development . Retrieved 2011, from M.S Ramaiah ,School of Advance Studies,INDIA.

4- Plhal, I. (n.d.)(2003). Nonlinear Static Analysis of Landing Gear According to FAR/JAR23 regulation. Retrieved 2011, from Brno Univesity of Technology ,Institute of Aerospace Engineering /Czech Republic.

5- Morrison, D., Neff, G., \& Zahraee, M. (1995). Landing gear Simulation and Analysis. Retrieved 2011, from Allied Signal/McNair Summer Undergraduate Research Intership.

6- Raymer ,D.P. (1999).Aircraft design: A conceptual Approach .Ohio/USA:AIAA

7- Di Milano, P. (2009). landing gear design numerical models for aircraft system . Retrieved 2011, from Department of aerospace .Milano University

8- Cessna 152 Data Sheet .

9- PATRAN/NASTRAN, manual help guide.

The work was carried out at the college of Engineering. University of Mosul 